OPEN ACCESS

Edited by:

Jean Paul Deslypere, Aesculape CRO, Belgium

Reviewed by:

Željko Reiner,

University Hospital Centre Zagreb,

Croatia

Massimiliano Ruscica,

University of Milan, Italy

*Correspondence:

Hong Zhu

hongzhumao@sohu.com

Dongye Li

dongyeli@xzhmu.edu.cn

Specialty section: This article was submitted to Drugs Outcomes Research and

Policies,

a section of the journal

Frontiers in Pharmacology

Received: 21 May 2021 Accepted: 05 October 2021 Published: 21 October 2021

Citation:

Ma W, Pan Q, Pan D, Xu T, Zhu H and LiD (2021) Efficacy and Safety of LipidLowering Drugs of Different Intensity on Clinical Outcomes: A Systematic Review and Network Meta-Analysis.

Front. Pharmacol. 12:713007. doi: 10.3389/fphar.2021.713007

\section{Efficacy and Safety of Lipid-Lowering Drugs of Different Intensity on Clinical Outcomes: A Systematic Review and Network Meta-Analysis}

\author{
Wenrui Ma ${ }^{1}$, Qinyuan Pan ${ }^{1}$, Defeng $\mathrm{Pan}^{2}$, Tongda $\mathrm{Xu}^{2}$, Hong $\mathrm{Zhu^{2* }}$ and Dongye $\mathrm{Li}^{1,2 *}$ \\ ${ }^{1}$ Institute of Cardiovascular Disease Research, Xuzhou Medical University, Xuzhou, China, ${ }^{2}$ Xuzhou Medical University Affiliated \\ Hospital, Xuzhou, China
}

There have been many meta-analyses for statins, ezetimibe and proprotein convertase subtilisin/kexin type 9 inhibitors (PCSK9i) to evaluate clinical outcomes, but the efficacy and safety of different intensity of these three drugs on clinical outcomes was absent. PCSK9i, ezetimibe, and statins were divided into seven interventions as follows: including PCSK9i + high-intensity statins (P9i+HT), PCSK9i + moderate-intensity statins (P9i+MT), ezetimibe + high-intensity statins $(E z e+H T)$, ezetimibe + moderate-intensity statins (Eze+MT), highintensity statins $(\mathrm{HT})$, moderate-intensity statins (MT), and low-intensity statins (LT). The risk ratios $(\mathrm{RR})$ and 95\% confidence intervals $(\mathrm{Cl})$ were calculated to evaluate the clinical outcomes in all randomized controlled trials included. In traditional meta-analysis, the more intensive treatment had a lower risk of all-cause mortality (RR 0.91, 95\% Cl 0.88-0.95), cardiovascular mortality (RR 0.89, 95\% Cl 0.86-0.92), myocardial infarction (RR 0.79, 95\% $\mathrm{Cl} 0.77-0.81$ ), coronary revascularization (RR $0.80,95 \% \mathrm{Cl} 0.76-0.84)$, and cerebrovascular events (RR 0.84, 95\% Cl 0.80-0.88) compared with the less intensive treatment. However, the more intensive treatment had a higher risk of new-onset diabetes (RR 1.08, 95\% Cl 1.041.12). The network meta-analysis demonstrated that P9i+HT, P9i+MT, HT, and MT were significantly associated with a risk reduction in coronary revascularization and cerebrovascular events compared with PLBO. LT could effectively reduce the risk of cardiovascular mortality (RR 0.71, 95\% Cl 0.54-0.92), MI (RR 0.67, 95\% Cl 0.54-0.82), and coronary revascularization (RR 0.77, 95\% $\mathrm{Cl} 0.65-0.91$ ) compared with PLBO. P9i+HT was superior to $\mathrm{HT}$ in reducing the risk of $\mathrm{Ml}(\mathrm{RR} 0.78,95 \% \mathrm{Cl} 0.68-0.90)$, coronary revascularization (RR 0.84, 95\% Cl 0.73-0.96), and cerebrovascular events (RR 0.78, 95\% $\mathrm{Cl}$ 0.64-0.95). However, compared with PLBO, P9i+HT, HT, and MT could increase the risk of new-onset diabetes (RR 1.23, 95\% Cl 1.11-1.37; RR 1.23, 95\% Cl 1.14-1.33; RR 1.09, $95 \% \mathrm{Cl} 1.02-1.15$, respectively). In conclusion, PCSK9i added to background statins may be recommended as preferred lipid-lowering therapy, and did not increase the additional risk of new-onset diabetes. The safety and efficacy of ezetimibe was not superior to that of statins. LT can be recommended as the initial therapy.

Keywords: lipid-lowering drugs, all-cause mortality, cardiovascular diseases, PCSK9 inhibitors, network metaanalysis 


\section{INTRODUCTION}

Lipid-lowering drugs, which are pivotal in the treatment of atherosclerotic cardiovascular diseases (ASCVD), can reduce major adverse cardiovascular events (MACE) to a certain extent (Bonovas et al., 2011). Currently, the clinically recommended lipid-lowering drugs are statins, ezetimibe, and proprotein convertase subtilisin/kexin type 9 inhibitors (PCSK9i) (Ruscica et al., 2021). As the commonly used lipid-lowering drugs since the mid-1980s, statins can decrease low-density lipoprotein cholesterol (LDL-C) levels (Reiner, 2013). However, LDL-C levels cannot be reduced to ESC/EAS guidelines in many patients by statins-alone (Mach et al., 2020). Therefore, ezetimibe, an inhibitor of cholesterol absorption, is added to further reduce LDL-C levels within the background of statin therapy (Cannon et al., 2015). In addition, there are many patients whose LDL-C levels cannot be reduced to target levels, even with the addition of ezetimibe, but the use of PCSK9i can further reduce LDL-C levels and the risk of clinical outcomes (AlTurki et al., 2019). Moreover, similar clinical benefits can be achieved for PCSK9i, alirocumab and evolocumab, which are currently used clinically (Guedeney et al., 2021). For patients with hypercholesterolemia, the use of the PCSK9i greatly alleviates the harm caused by high LDL-C levels (Navarese et al., 2018; Reiner, 2018).

Previous meta-analyses have reported the direct comparison of two of the three drugs but did not clarify the effects of different drug types and their intensity on the clinical outcomes. In general, clinicians establish the drug protocol based on the patient's LDLC level. Currently, statins can be divided into three levels according to the degree to which they lower LDL-C levels, namely, high intensity, moderate intensity, and low intensity (Stone et al., 2014). Moderate-intensity statins are the most commonly used. A previous network meta-analysis reported that high-intensity statins can significantly reduce LDL-C levels but did not clarify the effects of statins of different intensity on clinical outcomes (Khan et al., 2018). Moreover, Toth et al. analyzed the effects of PCSK9i and ezetimibe on LDLC levels but did not compare the clinical outcomes (Toth et al., 2017). Therefore, this network meta-analysis aims to determine which lipid-lowering therapy can achieve the best effect for different clinical outcomes.

\section{METHODS}

This network meta-analysis followed the PRISMA Statement (Moher et al., 2009) and was registered with PROSPERO (CRD42021244226).

\section{Objectives, Data Sources, and Search Strategies}

This network meta-analysis evaluated the effects of three types of commonly used lipid-lowering drugs on clinical outcomes. We searched embase, PubMed, and Cochrane databases up to March 2021 and for terms relevant to statins, ezetimibe, PCSK9 inhibitors, and randomized controlled trials. The search entries were adjusted to apply to each database, and all terms were imported into Endnote X9 for manual screening according to the inclusion criteria (Supplementary Table S1).

\section{Study Selection and Data Abstraction}

Many studies related to lipid-lowering drugs are restricted by a small number of participants and short duration, which often brings uncertainty to the study results. We set the inclusion criteria to studies including $>500$ participants, lasting at least 48 weeks, and reporting one or more outcomes, such as all-cause mortality, cardiovascular mortality, myocardial infarction (MI), coronary revascularization, cerebrovascular events, cancer, and new-onset diabetes. The eligible trials included a comparison of at least one of the drugs, namely, statins, ezetimibe, and PCSK9i. Bococizumab, a PCSK9i, was excluded because of the existence of anti-drug antibodies and the attenuation of the lipid-lowering effect during treatment (Ridker et al., 2017). Two investigators independently assessed the terms to avoid bias in the data search and abstraction process. The opinion of a third investigator was sought in case of disagreement. We extracted the name and year of all studies, the total number of participants, the follow-up time, the intervention measures of the intervention and control group, the baseline and endpoint LDL-C levels, and the number of events with outcomes in the eligible studies. Studies with a follow-up time of at least 48 weeks were included because the clinical outcomes were divergent at approximately 1 year after drug use (Sever et al., 2003; Koren and Hunninghake, 2004).

\section{Interventions}

The three drug categories in the selected studies were divided into seven interventions for comparison as follows: PCSK9i + highintensity statins $(\mathrm{P} 9 \mathrm{i}+\mathrm{HT})$, PCSK9 $\mathrm{i}+$ moderate-intensity statins $(\mathrm{P} 9 \mathrm{i}+\mathrm{MT})$, ezetimibe + high-intensity statins $($ Eze $+\mathrm{HT})$, ezetimibe + moderate-intensity statins (Eze + MT), highintensity statins (HT), moderate-intensity statins (MT), and low-intensity statins (LT).

\section{Data Analysis}

STATA 13.0 software was used to conduct frequentist network meta-analysis. RR and $95 \% \mathrm{CI}$ values were calculated to evaluate the clinical outcomes. We used the surface under the cumulative ranking curve (SUCRA) to rank which drugs could achieve the relatively better therapeutic effect in different clinical outcomes. The inconsistent model was used to test the data, and P-value > 0.05 indicated no inconsistency. The consistency of the direct and indirect comparison results was evaluated by the inconsistency factor (IF) and 95\% CI. $\mathrm{I}^{2}$ values were determined to assess the statistical heterogeneity in the paired meta-analysis conducted by Review Manager 5.2 software. Heterogeneity existed if $\mathrm{I}^{2} \geq 50 \%$. The Cochrane Manual was used to evaluate the quality of each eligible trial, which was divided into high, unclear, and low risk of bias. Funnel plots were used to estimate the publication bias. In studies of PCSK9i, we used the intensity of the statins with the highest number of participants as the background statin intensity. When there were zero incidents in one arm of the study, we added 0.5 to each arm and performed the Haldane method (Sheehe, 1966). 
TABLE 1 | Characteristics of trials final included in the network meta-analysis.

\begin{tabular}{|c|c|c|c|c|c|c|c|c|}
\hline \multirow[t]{2}{*}{ Study } & \multirow{2}{*}{$\begin{array}{c}\text { Total } \\
\text { patients }\end{array}$} & \multirow{2}{*}{$\begin{array}{l}\text { Follow-up } \\
\text { (years) }\end{array}$} & \multicolumn{3}{|c|}{ Intervention } & \multicolumn{3}{|c|}{ Control } \\
\hline & & & Treatment & $\begin{array}{l}\text { Baseline } \\
\text { LDL-C } \\
\text { (mmol/L) }\end{array}$ & $\begin{array}{c}\text { Achieved } \\
\text { LDL-C } \\
\text { (mmol/L) }\end{array}$ & Treatment & $\begin{array}{l}\text { Baseline } \\
\text { LDL-C } \\
\text { (mmol/L) }\end{array}$ & $\begin{array}{c}\text { Achieved } \\
\text { LDL-C } \\
\text { (mmol/L) }\end{array}$ \\
\hline Wanner et al. (2005) & 1,255 & 4 & Atorvastatin 20 mg & 3.2 & 1.9 & Placebo & 3.3 & 3.1 \\
\hline 4S. Group (1994) & 4,444 & 5.4 & Simvastatin 20-40 mg & 4.9 & 3.2 & Placebo & 4.9 & 4.8 \\
\hline de Lemos et al. (2004) & 4,497 & 2 & Simvastatin 80 mg & 2.9 & 1.7 & $\begin{array}{l}\text { Simvastatin } \\
20 \mathrm{mg}\end{array}$ & 2.9 & 2.1 \\
\hline Downs et al. (1998) & 6,605 & 5.2 & Lovastatin 20-40 mg & 3.9 & 3.0 & Placebo & 3.9 & 3.7 \\
\hline Holdaas et al. (2003) & 2,102 & 5.1 & Fluvastatin 40-80 mg & 4.1 & 2.8 & Placebo & 4.1 & 3.8 \\
\hline $\begin{array}{l}\text { T. A. O. a. C. f. t. A. C. R. } \\
\text { Group (2002) }\end{array}$ & 10,355 & 4.8 & Pravastatin $40 \mathrm{mg}$ & 3.8 & 2.7 & Usual care & 3.8 & 3.6 \\
\hline $\begin{array}{l}\text { Koren and Hunninghake } \\
\text { (2004) }\end{array}$ & 2,442 & 4.3 & Atorvastatin 40-80 mg & 3.8 & 2.5 & Usual care & 3.8 & 2.9 \\
\hline Sever et al. (2003) & 10,305 & 3.3 & Atorvastatin 10 mg & 3.4 & 2.2 & Placebo & 3.4 & 3.2 \\
\hline Knopp et al. (2006) & 2,410 & 4.25 & Atorvastatin 10 mg & 2.9 & 2 & Placebo & 3.0 & 2.9 \\
\hline Fellström et al. (2009) & 2,773 & 3.2 & Rosuvastatin 10 mg & 2.6 & 1.5 & Placebo & 2.6 & 2.6 \\
\hline Colhoun et al. (2004) & 2,841 & 4 & Atorvastatin 10 mg & 3.0 & 2.1 & Placebo & 3.1 & 2.6 \\
\hline Sacks et al. (1996) & 4,159 & 5 & Pravastatin 40 mg & 3.6 & 2.5 & Placebo & 3.6 & 3.5 \\
\hline Kjekshus et al. (2007) & 5,011 & 3 & Rosuvastatin 10 mg & 3.6 & 2.0 & Placebo & 3.6 & 3.6 \\
\hline Kastelein et al. (2008) & 720 & 2 & $\begin{array}{l}\text { Ezetimibe } 10 \mathrm{mg}+ \\
\text { simvastatin } 80 \mathrm{mg}\end{array}$ & 8.2 & 3.7 & $\begin{array}{l}\text { Simvastatin } \\
80 \mathrm{mg}\end{array}$ & 8.2 & 5.0 \\
\hline Liem et al. (2002) & 540 & 1 & Fluvastatin 80 mg & 3.5 & 2.7 & Placebo & 3.6 & 3.9 \\
\hline Sabatine et al. (2017) & 27,564 & 2.2 & Evolocumab & 2.4 & 0.8 & high statins & 2.4 & 2.4 \\
\hline Tavazzi et al. (2008) & 4,574 & 3.9 & Rosuvastatin 10 mg & 3.9 & 3.3 & Placebo & 3.9 & 3.8 \\
\hline Investigators (2000) & 4,271 & 2 & Pravastatin 20 mg & 3.9 & 3.3 & Usual care & 3.9 & 3.8 \\
\hline Nicholls et al. (2016) & 968 & 1.5 & Evolocumab & 2.4 & 0.9 & high statins & 2.4 & 2.4 \\
\hline Athyros et al. (2002) & 1,600 & 3 & Atorvastatin 10-80 mg & 4.7 & 2.5 & Usual care & 4.7 & 4.4 \\
\hline Hagiwara et al. (2017) & 1721 & 3.9 & $\begin{array}{l}\text { Ezetimibe } 10 \mathrm{mg}+ \\
\text { Pitavastatin } 2 \mathrm{mg}\end{array}$ & 3.5 & 1.7 & $\begin{array}{l}\text { Pitavastatin } \\
2 \mathrm{mg}\end{array}$ & 3.5 & 2.2 \\
\hline Yusuf et al. (2016) & 12,705 & 5.6 & Rosuvastatin 10 mg & 3.3 & 2.4 & Placebo & 3.3 & 3.2 \\
\hline $\begin{array}{l}\text { ALLHAT Collaborative } \\
\text { Research Group. (2002) }\end{array}$ & 20,536 & 5 & Simvastatin 40 mg & 3.4 & 2.4 & Placebo & 3.4 & 3.1 \\
\hline Pedersen et al. (2005) & 8,888 & 4.8 & Atorvastatin 80 mg & 3.1 & 2.1 & $\begin{array}{l}\text { Simvastatin } \\
20 \mathrm{mg}\end{array}$ & 3.1 & 2.6 \\
\hline Cannon et al. (2015) & 18,144 & 6 & $\begin{array}{l}\text { Ezetimibe } 10 \mathrm{mg}+ \\
\text { Simvastatin } 40 \mathrm{mg}\end{array}$ & 2.4 & 1.3 & $\begin{array}{l}\text { Simvastatin } \\
40 \mathrm{mg}\end{array}$ & 2.4 & 1.8 \\
\hline Hosomi et al. (2015) & 1,578 & 4.9 & Pravastatin 10 mg & 3.4 & 2.7 & Placebo & 3.4 & 3.2 \\
\hline Ridker et al. (2008) & 17,802 & 4 & Rosuvastatin 20 mg & 2.8 & 1.5 & Placebo & 2.8 & 2.8 \\
\hline L. S. GROUP (1998) & 9,014 & 6.1 & Pravastatin 40 mg & 3.9 & 2.9 & Placebo & 3.9 & 3.9 \\
\hline Serruys et al. (2002) & 1,677 & 3.9 & Fluvastatin 80 mg & 3.4 & 2.5 & Placebo & 3.4 & 3.0 \\
\hline Nakamura et al. (2006) & 7,832 & 5.3 & Pravastatin $10-20 \mathrm{mg}$ & 4.1 & 3.3 & Diet & 4.1 & 3.7 \\
\hline Crouse et al. (2007) & 984 & 2 & Rosuvastatin 40 mg & 4.0 & 2.0 & Placebo & 4.0 & 4.0 \\
\hline Cannon et al. (2015) & 720 & 2 & Alirocumab & 2.8 & 1.3 & Ezetimibe & 2.7 & 2.2 \\
\hline Robinson et al. (2015) & 2,341 & 1.5 & Alirocumab & 3.1 & 1.5 & high statins & 3.1 & 3.2 \\
\hline Schwartz et al. (2018) & 18,924 & 2.8 & Alirocumab & 2.4 & 1.4 & high statins & 2.4 & 2.7 \\
\hline Sabatine et al. (2015) & 4,465 & 0.9 & Evolocumab & 3.1 & 1.2 & $\begin{array}{l}\text { Moderate } \\
\text { statins }\end{array}$ & 3.1 & 3.1 \\
\hline Patients (1993) & 1,062 & 1 & Pravastatin 20 mg & 4.7 & 3.5 & Placebo & 4.7 & 4.7 \\
\hline Shepherd et al. (2002) & 5,804 & 3.2 & Pravastatin 40 mg & 3.8 & 2.5 & Placebo & 3.8 & 3.6 \\
\hline Cannon et al. (2004) & 4,162 & 2 & Atorvastatin 80 mg & 2.7 & 1.6 & $\begin{array}{l}\text { Pravastatin } \\
40 \mathrm{mg}\end{array}$ & 2.7 & 2.5 \\
\hline Jukema et al. (1995) & 884 & 2 & Pravastatin 40 mg & 4.3 & 3.2 & Placebo & 4.3 & 4.4 \\
\hline Nissen et al. (2004) & 654 & 1.5 & Atorvastatin 80 mg & 3.0 & 2.1 & $\begin{array}{l}\text { Pravastatin } \\
40 \mathrm{mg}\end{array}$ & 3.9 & 3.9 \\
\hline Armitage et al. (2010) & 12,064 & 6.7 & Simvastatin 80 mg & 2.5 & 2.2 & $\begin{array}{l}\text { Simvastatin } \\
20 \mathrm{mg}\end{array}$ & 2.5 & 2.5 \\
\hline Rossebø et al. (2008) & 1873 & 2 & $\begin{array}{l}\text { Ezetimibe } 10 \mathrm{mg}+ \\
\text { Simvastatin } 40 \mathrm{mg}\end{array}$ & 3.6 & 1.7 & Placebo & 3.6 & 3.5 \\
\hline Baigent et al. (2011) & 9,270 & 4.9 & $\begin{array}{l}\text { Ezetimibe } 10 \mathrm{mg}+ \\
\text { Simvastatin } 20 \mathrm{mg}\end{array}$ & 2.8 & 1.9 & Placebo & 2.8 & 2.7 \\
\hline Amarenco et al. (2006) & 4,731 & 4.9 & Atorvastatin $80 \mathrm{mg}$ & 3.4 & 1.9 & Placebo & 3.5 & 3.3 \\
\hline LaRosa et al. (2005) & 10,001 & 4.9 & Atorvastatin 80 mg & 2.5 & 2.0 & $\begin{array}{l}\text { Atorvastatin } \\
10 \mathrm{mg}\end{array}$ & 2.5 & 2.6 \\
\hline Shepherd et al. (1995) & 6,595 & 4.9 & Pravastatin 40 mg & 5.0 & 3.7 & Placebo & 5.0 & 4.9 \\
\hline
\end{tabular}

LDL-C, low-density lipoprotein cholesterol. 


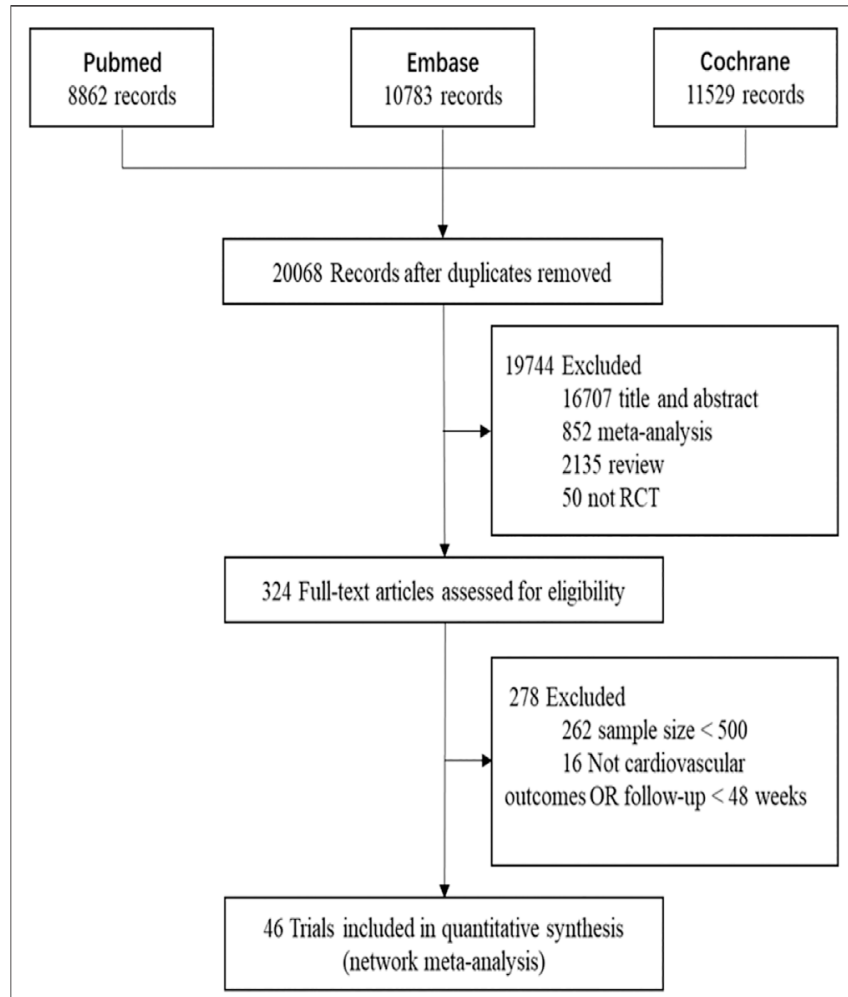

FIGURE 1 | The process of search and selection of randomized controlled trials for network meta-analysis in the flow chart. RCT, randomized controlled trials.

\section{RESULTS}

In this network meta-analysis, 46 two-arm studies were included (Table 1). Figure 1 shows the search results of the three databases, the eliminative conditions, and the trials included for analysis. Among the eligible studies, the intervention group was comprised of five studies of P9i $+\mathrm{HT}$, one study of P9i + MT, one study of Eze + HT, four studies of Eze + MT, 11 studies of HT, 18 studies of MT, and six studies of LT. Most of the selected studies were secondary prevention and mixed prevention in nature, and the mean follow-up time was 3.61 years.

The Cochrane Risk of Bias Tool was used to examine the quality of each selected trial, and $74.8,16.8$, and $8.4 \%$ of the studies were considered as low risk, unclear risk, and high risk, respectively. The risk of studies was mainly caused by blind assignments and other bias during the trial design (Supplementary Figure S1). The funnel plots did not show publication bias (Supplementary Figures S2, S3). Allcause mortality and coronary revascularization showed statistical heterogeneity, with $\mathrm{I}^{2}$ values of 57 and $63 \%$, respectively. There were no inconsistencies in direct and indirect comparisons among all outcomes. The network meta-analysis of the clinical outcomes is summarized in Table 2, and the results of the SUCRA rank on all the clinical outcomes is presented in Figure 2.

\section{Primary Outcomes}

Forty-six and 42 studies were evaluated for the risk of all-cause mortality and cardiovascular mortality, with 283,867 and 281,305 participants, respectively. The meta-analysis showed that the more intensive treatment could significantly reduce all-cause mortality (RR 0.91, 95\% CI 0.88-0.95) and cardiovascular mortality (RR 0.89 , 95\% CI 0.86-0.92) compared with the less intensive treatment (Supplementary Figures S4, S5).

The network plots of seven interventions for all-cause mortality are presented in Figure 3A. Compared with PLBO, the network metaanalysis showed that P9i + HT (RR 0.76, 95\% CI 0.63-0.93), HT (RR 0.83 , 95\% CI 0.75-0.92), and MT (RR 0.92, 95\% CI 0.87-0.98) significantly reduced all-cause mortality. HT associated with a $10 \%$ (RR 0.90, 95\%CI 0.82-0.99) risk reduction in all-cause mortality compared with MT. The network meta-analysis of secondary prevention showed that $\mathrm{P} 9 \mathrm{i}+\mathrm{HT}$ associated with a $31 \%$ risk reduction (RR 0.69, 95\% CI 0.51-0.94), whereas HT associated with a $22 \%$ risk reduction (RR $0.78,95 \%$ CI $0.65-0.93$ ) compared with PLBO (Figure 3B). P9i + HT and P9i + MT ranked as the most effective treatments in reducing all-cause mortality for secondary prevention and all populations, respectively (SUCRA 86.0 and 95.3\%).

The efficacy of seven interventions in reducing cardiovascular mortality was similar to that of all-cause mortality (Figure 3C). P9i + HT, LT, HT, and MT associated with 33\% (RR 0.67, 95\% CI 0.54-0.85), 29\% (RR 0.71, 95\% CI 0.54-0.92), 28\% (RR 0.72, 95\% CI $0.64-0.82$ ), and $15 \%$ (RR $0.85,95 \%$ CI 0.79-0.91) risk reduction in cardiovascular mortality compared with PLBO, respectively. Moreover, HT reduced the risk of cardiovascular mortality by $14 \%$ (RR 0.86, 95\% CI 0.76-0.96) compared with MT. The network meta-analysis of secondary prevention showed that P9i $+\mathrm{HT}$ reduced the risk of cardiovascular mortality by $35 \%$ (RR 0.65 , 95\% CI $0.53-0.80$ ), HT by $31 \%$ (RR 0.69, 95\% CI 0.60-0.79), Eze + MT by $26 \%$ (RR0.74, 95\% CI 0.61-0.88), and MT by 26\% (RR 0.74, 95\% CI 0.66-0.82) compared with PLBO (Figure 3D), with P9i + $\mathrm{HT}$ ranking as the most effective drug in all population and secondary prevention (SUCRA 79.3 and $88.0 \%$ ).

\section{Secondary Outcomes}

Traditional meta-analysis showed that the more intensive treatment could reduce the risk of MI, coronary revascularization, and cerebrovascular events compared with the less intensive treatment (Supplementary Figures S6-S8).

In total, 283,867 participants from 46 studies provided the MI data in the network meta-analysis of seven interventions. Compared with PLBO, P9i + HT (RR 0.48, 95\% CI 0.40-0.58), HT (RR 0.62, 95\% CI 0.55-0.69), LT (RR 0.67, 95\% CI 0.54-0.82), Eze + MT (RR $0.74,95 \%$ RR $0.64-0.86$ ), and MT (RR 0.76, 95\% CI 0.71-0.81) could effectively reduce the risk of MI. HT associated with lower MI risk than MT (RR 0.81, 95\% CI 0.74-0.89) and Eze + MT (RR 0.83, 95\% CI 0.79-0.99). The risk of MI in patients who received P9i + HT was significantly reduced compared with those who received Eze + MT (RR 0.65, 95\% CI 0.52-0.82) and different intensity statins (HT, RR 0.78, 95\% CI 0.68-0.90; MT, RR 0.63, 95\% CI 0.53-0.75; LT, RR 0.72, 95\% CI 0.55-0.95) (Supplementary Figure S9). Compared with other interventions, P9i + HT ranked first in reducing MI risk (SUCRA 86.2\%).

There were 276,077 participants from 42 studies in the network meta-analysis of seven interventions, which included coronary revascularization events. Compared with PLBO, P9i + MT reduced the relative risk of coronary revascularization by $65 \%$ 
TABLE 2 | Network meta-analysis for clinical outcomes included.

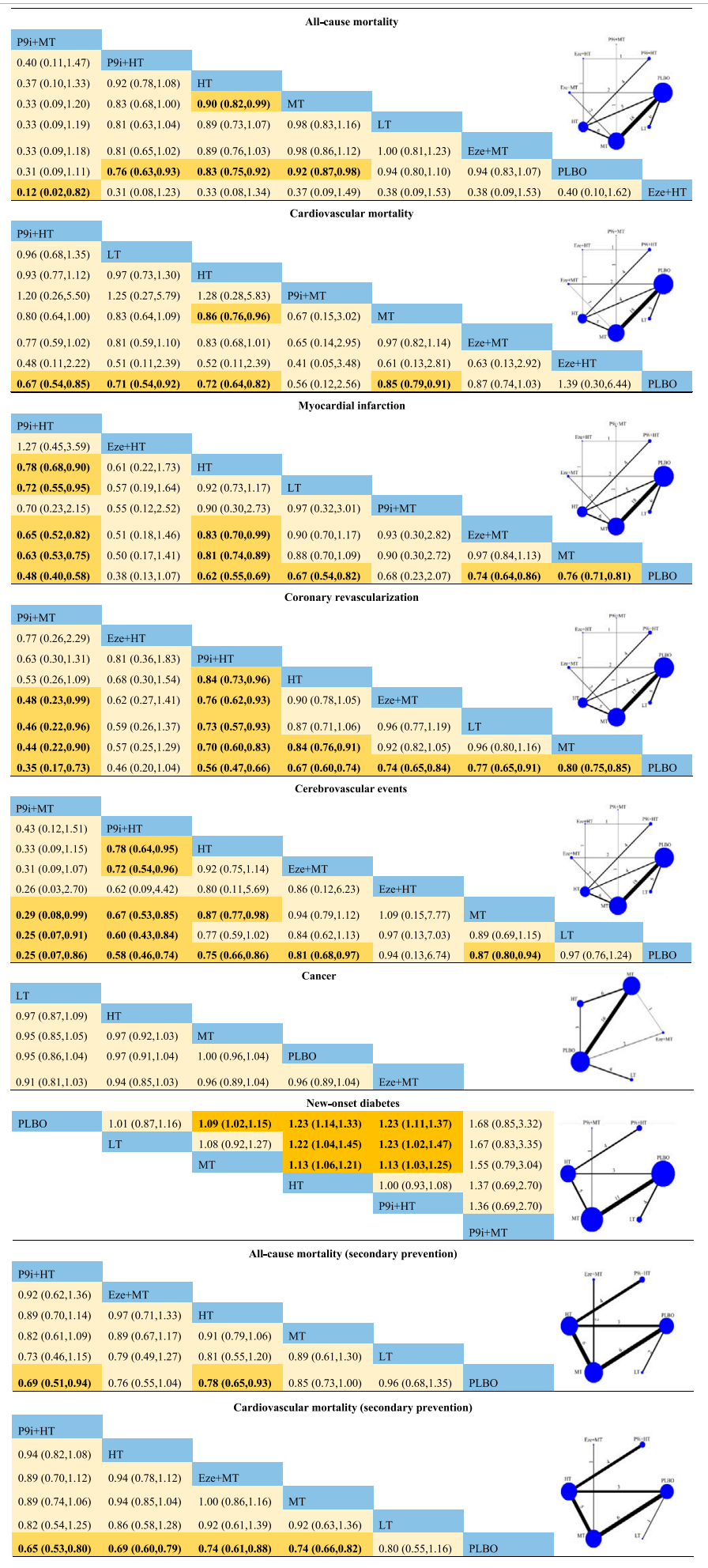

Each area represents the value of RR and $95 \% \mathrm{Cl}$. The blue area represents interventions; the orange area and bolded values represent statistically meaningful at the 0.05 significance level. The number perpendicular to the line between the two interventions represents the number of studies included. P9i + HT, PCSK9i + high-intensity statins; P9i + MT, PCSK $9 i+$ moderateintensity statins; Eze + HT, ezetimibe + high-intensity statins; Eze + MT, ezetimibe + moderate-intensity statins; $H T$, high-intensity statins; $M T$, moderate-intensity statins; $L T$, low-intensity statins; PLBO, placebo. 


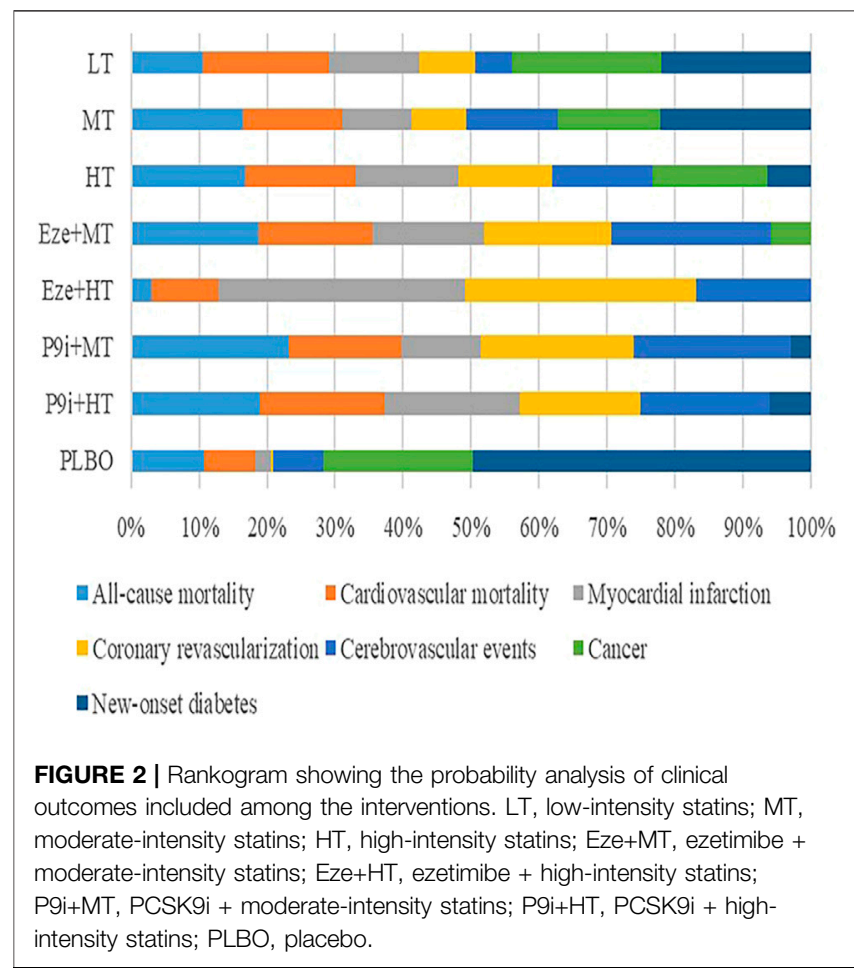

(RR 0.35, 95\% CI 0.17-0.73), P9i + HT by 44\% (RR 0.56, 95\% CI $0.47-0.66$ ), HT by $33 \%$ (RR $0.67,95 \%$ CI $0.64-0.83$ ), Eze + MT by $26 \%$ (RR $0.74,95 \%$ CI $0.65-0.84$ ), LT by $23 \%$ (RR $0.77,95 \%$ CI $0.65-0.91$ ), and MT by $20 \%$ (RR 0.80, 95\% CI 0.75-0.85) (Figure). $\mathrm{P} 9 \mathrm{i}+\mathrm{MT}$ caused a significant reduction in the risk of coronary revascularization by $52 \%$ (RR $0.48,95 \%$ CI $0.23-0.99$ ), by $54 \%$ (RR 0.46 , 95\% CI $0.22-0.96$ ), and by $56 \%$ (RR $0.44,95 \%$ CI 0.22-0.90), respectively, compared with Eze + MT, LT, and MT. Compared with HT, P9i + HT associated with $16 \%$ risk reduction in coronary revascularization (Supplementary Figure S10). Among the seven interventions, P9i + MT yielded the highest SUCRA rank $(92.3 \%)$ in reducing coronary revascularization events.

Forty-four studies, which included 281,305 participants provided the cerebrovascular event dates. The network metaanalysis showed that P9i + MT (RR 0.25, 95\% CI 0.07-0.86), P9i + HT (RR 0.58, 95\% CI 0.46-0.74), HT (RR 0.75, 95\% CI 0.66-0.86), Eze + HT (RR 0.81, 95\% CI 0.66-0.86), and MT (RR $0.87,95 \%$ CI $0.80-0.94$ ) had a lower risk of cerebrovascular events than PLBO (Figure). P9i + HT associated with higher benefits of cerebrovascular events compared with Eze + MT (RR 0.72, 95\% CI 0.54-0.96) and different intensity statins (HT, RR 0.78, 95\% CI 0.64-0.95; MT, RR 0.67, 95\% CI 0.53-0.85; LT, RR 0.60, 0.43-0.84). HT associated with a lower risk of cerebrovascular events than MT (RR 0.87, 95\% CI 0.77-0.98) (Supplementary Figure S11). Overall, P9i + MT had the highest probability of ranked best (SUCRA 95.1\%).

\section{Other Outcomes}

The cancer data was provided by 216,665 participants in 32 studies. The traditional meta-analysis described no statistical difference in the risk of cancer on lipid-lowering drugs (RR $0.99,95 \%$ CI $0.96-1.03, p=0.70, \mathrm{I}^{2}=1 \%$ ) (Supplementary Figure S12). In the network meta-analysis, there was no evidence that the seven interventions associated with the occurrence of cancer (Supplementary Figure S13).

Twenty-eight studies, which included 229,893 participants, provided the data new-onset diabetes data. The traditional metaanalysis showed that the more-intensive lipid-lowering drugs associated with a higher risk of new-onset diabetes compared with the less-intensive lipid-lowering drugs conducted by our meta-analysis (RR 1.08, 95\% CI 1.04-1.12, $p<0.001, \mathrm{I}^{2}=18 \%$ ) (Figure 4A). When participants received P9i + HT (RR 1.23, 95\% CI 1.11-1.37), HT (RR 1.23, 95\% CI 1.14-1.33), or MT (RR 1.09, 95\% CI 1.02-1.05), the likelihood of new-onset diabetes was significantly higher than that in participants who received PLBO (Supplementary Figure S14). P9i + MT might have been related to the occurrence of diabetes in terms of the SUCRA rank (11.8\%). However, our subgroup analysis showed that there was no significant difference between PCSK9i added to background statins and moderate-to-high intensity statins (RR 1.01, 95\% CI 0.94-1.08, $p=0.83$ ) (Figure 4B).

\section{DISCUSSION}

In the present network meta-analysis, we report that PCSK9i added to background moderate-to-high intensity statins was the most effective lipid-lowering drug in reducing the risk of mortality and cardiovascular-related events. P9i $+\mathrm{HT}$ associated with $24 \%$ and $33 \%$ risk reduction in all-cause and cardiovascular mortality compared with PLBO in all studies, respectively. These results agreed with the analysis of secondary prevention in our network meta-analysis. Whether PCSK9i can reduce mortality, however, is controversial (Schmidt et al., 2020). Our findings showed that PCSK9i added to background high-intensity statins was associated with a reduced risk of all-cause mortality and cardiovascular mortality. However, PCSK9i did not show the benefit of reducing mortality even in the reliable FOURIER (Sabatine et al., 2017) and ODYSSEY OUTCOMES trial (Schwartz et al., 2018). Statins, the most used drug, have been reported to be effective in reducing mortality in multiple studies. However, in our study, statins were not superior to PCSK9i in reducing the risk of mortality. The reason for this result might have been due to the fact that the included studies had follow-up periods of at least 48 weeks because clinical benefits had been shown to be evident at approximately 1 year after drug use. This compensated for the shortcomings of the previous meta-analysis due to the short follow-up time, and we confirmed the beneficial effect of PCSK9i on mortality. This provides support for the wide clinical application of PCSK9i. In contrast, Diaz R et al. found from ODYSSEY OUTCOMES trial that the intensity of statin background was not associated with a reduced risk of MACE from alirocumab (Diaz et al., 2021). Similar LDL-C baseline levels in ODYSSEY OUTCOMES trial may contribute to this result, as higher baseline LDL-C levels were associated with a greater reduction in risk of MACE (Navarese et al., 2018). At the 

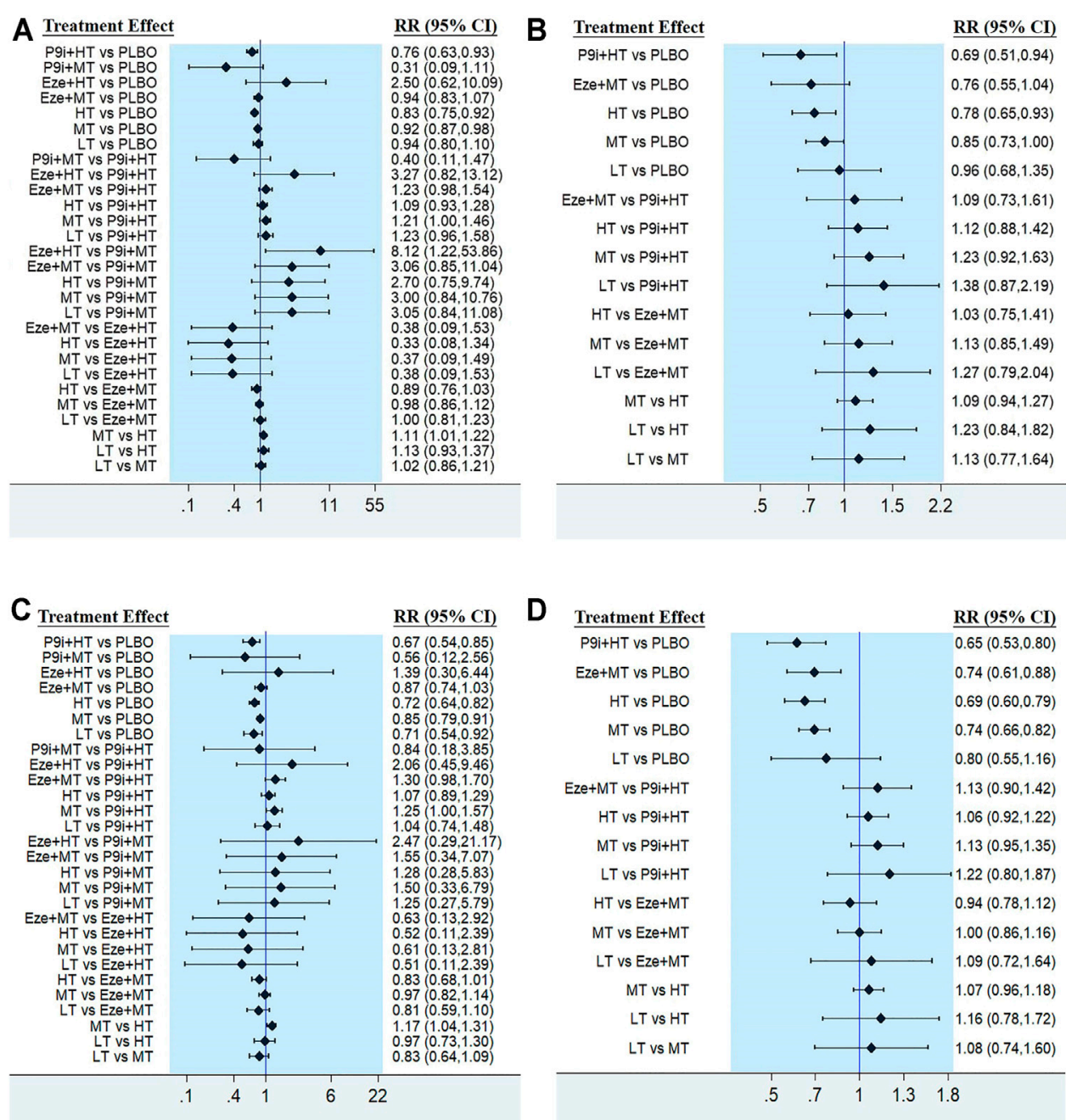

FIGURE 3 | Forest plots showing comparison among interventions for (A) All-cause mortality, (B) All-cause mortality of secondary prevention, (C) Cardiovascular mortality, (D) Cardiovascular mortality of secondary prevention. PLBO, placebo; P9i+HT, PCSK9i + high-intensity statins; P9i+MT, PCSK9i + moderate-intensity statins; Eze+HT, ezetimibe + high-intensity statins; Eze+MT, ezetimibe + moderate-intensity statins; HT, high-intensity statins; MT, moderate-intensity statins; LT, low-intensity statins; $\mathrm{RR}$, risk ratios; $\mathrm{Cl}$, confidence intervals.

same time, alirocumab achieved a similar relative reduction in LDL-C levels in subgroups with different intensity statin background, leading to no difference in the risk of MACE among the groups from ODYSSEY OUTCOMES trial. The combination of statin and PCSK9i is necessary, as statin therapy increases both PCSK9 and LDL receptor levels. More trials are needed in the future to determine whether the reduced risk of clinical outcome associated with PCSK9i is related to background statin intensity.

A major safety issue with regard to the use of PCSK9i was whether lowering LDL-C levels could cause neurocognitive disorders. Ying et al. (Ying et al., 2021), recent EBBINGHAUS study (Gencer et al., 2020) as well as the CANTAB study (Janik et al., 2021), reported that PCSK9i had no impact on cognitive impairment. The OSLER study (Sabatine et al., 2015), which involved background moderate-intensity statin therapy, reported frequent neurocognitive adverse events. At the same time, PCSK9i has been reported in many meta-analysis as associated with neurocognitive disorder (Harvey et al., 2018; Gouverneur et al., 2021). However, Khan and Raccah et al. performed that evidence of neurocognitive adverse events was found during follow-up periods (Hirsh Raccah et al., 2021; Khan et al., 2017). In our network meta-analysis, we were unable to analyze the adverse neurological events due to the few studies that reported relevant events. Therefore, the follow-up time should be increased to evaluate the relationship between PCSK9i and neurological adverse events. Another safety issue is whether lipid-lowering drugs affect the health or clinical benefits of elderlies (75 years and older). Fortunately, lipidlowering drugs treatment can be as effective in elderlies as they are in younger individuals (Collaboration, 2019; Gencer et al., 2020). Moreover, C-reactive protein (CRP) and 

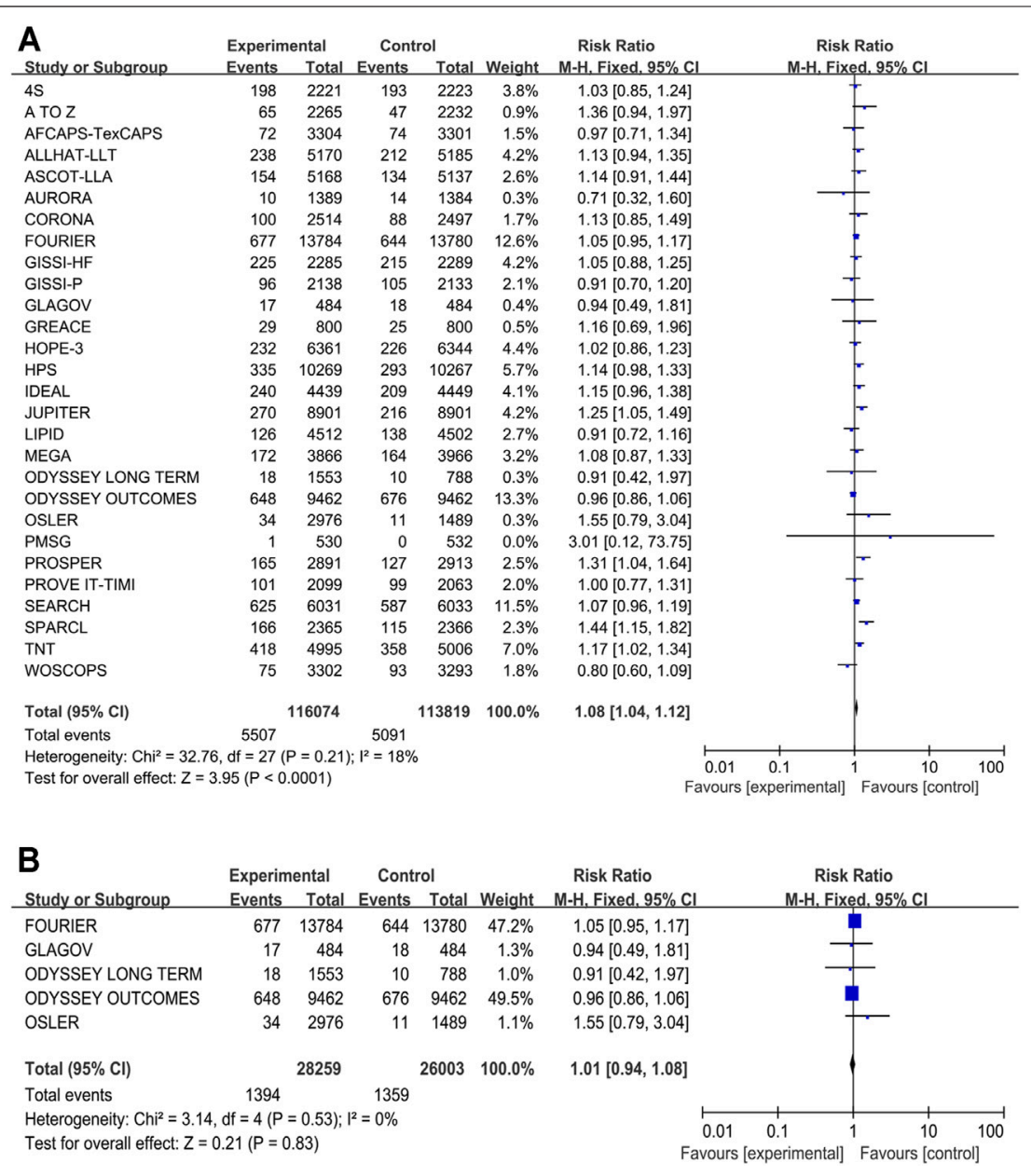

FIGURE 4 | Meta-analysis of new-onset diabetes. (A) Forest plots of new-onset diabetes between the more intensive treatment and the less intensive treatment. (B) Subgroup meta-analysis of new-onset diabetes between PCSK9 inhibitors and statins. Cl, confidence interval.

lipoprotein(a) as risk factors for ASCVD. The CRP is an important inflammatory factor in the development of ASCVD, but there were no studies showing that PCSK9i affects CRP level (Ruscica et al., 2019). In the trials of PCSK9i, changes in the CRP level might have been caused by the background statins treatment. Lipoprotein(a) plays an independent risk factor for ASCVD. Lowering lipoprotein(a) $1.7 \mathrm{mmol} / \mathrm{L}$ could achieve similar cardiovascular benefits of reducing LDL-C levels by $1 \mathrm{mmol} / \mathrm{L}$, but statins have not been shown to have a reduced lipoprotein(a) effect (Lamina and Kronenberg, 2019; Ruscica et al., 2021). PCSK9i, which co-downregulated lipoprotein(a) and LDL-C levels, has also been shown to obtain more clinical benefits (O’Donoghue et al., 2019). Unfortunately, the mechanism by which reduces lipoprotein(a) remains unknown.

Ezetimibe could further reduce LDL-C levels by $30 \%$ compared with statins alone. The IMPROVE-IT study presented the ezetimibe could improve cardiovascular outcomes and reduce the risk of adverse events (Cannon et al., 2015). However, there were no clinical benefits of ezetimibe added to background statins over statins alone. The reason for this result might be that ezetimibe was not widely used and the follow-up time was shorter than that of statins, such that its clinical benefits are not evident. Besides, the SEAS study showed that ezetimibe can increase the risk of cancer (Rossebø et al., 2008). No lipid-lowering drug was found to be associated with an increased risk of cancer in our analysis. Therefore, further studies are needed to verify the clinical benefits of ezetimibe.

In our network meta-analysis, we found that LT could effectively reduce the risk of cardiovascular mortality, MI, and coronary revascularization, and fortunately, it did not increase the risk of cancer and new-onset diabetes. LT had a higher probability of associating with lower MI risk than P9i + MT and Eze + MT in our network meta-analysis. It was an indisputable fact that PCSK9i and ezetimibe could significantly reduce LDL-C levels than LT. However, a recent study reported that ApoB was a more accurate marker of myocardial infarction than LDL-C (Johannesen et al., 2021). Therefore, exclusive use of the degree of lowered LDL-C level is insufficient to evaluate the risk of MI. This clinical outcome might have been related to the lifestyle and baseline body weight of the individuals. Moreover, the MEGA trial stated that low-intensity statins could achieve the same benefits as high-intensity statins in primary prevention in 
Japanese individuals (Nakamura et al., 2006), suggesting that different sensitivities to statin therapy might exists in different regions and races. Patients at risk of ASCVD are often initially treated with moderate-intensity statins. As such, the results of our network meta-analysis provide a basis for lowering blood lipids with LT for initial therapy.

We found that the risk of new-onset diabetes was associated with P9i $+\mathrm{HT}, \mathrm{HT}$, and MT. The reason for this result might be related to LDL-C level. Da Dalt et al. showed that PCSK9 deficiency could limit insulin secretion, leading to hyperglycemia (Da Dalt et al., 2019). Moreover, a recent study reported that depression caused an increase in PCSK9 level, which lead to insulin resistance (Macchi et al., 2020). However, Khan et al. (Khan et al., 2019), as well as a subanalysis from FOURIER trial (Sabatine et al., 2017), reported that PCSK9i, the most effective lipid-lowering drug, did not increase the risk of diabetes. Chiu et al. also stated that PCSK9i was not associated with the risk of diabetes (Chiu et al., 2020). Besides, PCSK9i added to background statins could increase the risk of new-onset diabetes, which might have been due to statin use. Our analysis confirmed that PCSK9i did not increase the additional risk of new-onset diabetes compared with statins, which had a conflicting conclusions of JUPITER (Ridker et al., 2008) and WOSCOPS (Shepherd et al., 1995) trials on the involvement of statins in the risk of diabetes. We found that HT was more likely to induce diabetes than low-tomoderate intensity statins. Wang et al. demonstrated that more intensive statins might increase the risk of new-onset diabetes by $18 \%$ (Wang et al., 2017). In the included studies, the high-intensity statins were atorvastatin ( $\geq 40 \mathrm{mg}$ ), rosuvastatin $(\geq 20 \mathrm{mg}$ ), and simvastatin $(\geq 80 \mathrm{mg}$ ) (Stone et al., 2014), suggesting that these high-intensity statins might be correlated with new-onset diabetes. However, the specific mechanism by which statins cause diabetes is still unclear. Therefore, in the long-term use of statins, blood glucose monitoring should be carried out. In addition, the mechanism of its occurrence should be thoroughly explored, and whether this situation can be improved by the use of combination drugs.

Of course, statins are often used in combination with other non-statins, in addition to PCSK9i and ezetimibe, which are commonly used. Recent network analysis performed that non-statin drugs, such as omega-3 fatty acids, bile acid sequestrants, and fibrates, when combined with statins, did not have positive effects on cardiovascular outcomes; instead, they increased the incidence of adverse events (Hoang and Kim, 2020; Kim et al., 2020). The demands for non-statin lipid-lowering drugs have increased due to statin-related muscle symptoms, hepatobiliary side-effects, and familial hypercholesterolemia. Inclisiran, a siRNA targeting PCSK9, can reduce LDL-C levels and is currently in the rapid development stage (Khan et al., 2020). Evinacumab is an anti-ANGPTL3 monoclonal antibody, which has been used in the treatment of familial hypercholesterolemia (Raal et al., 2020). As many lipid-lowering drugs are gradually introduced into use, we should pay more attention to the long-term efficacy and safety of these drugs, and their ability to treat or halt the occurrence of adverse events.

We reviewed studies of PCSK9i and found that the trials on the combined use of PCSK9i and ezetimibe were absent. The guidelines showed that if maximally tolerant statins and ezetimibe could not achieve target LDL-C levels, then PCSK9i was recommended for use. However, there were no studies on the combined use of PCSK9i and ezetimibe with or without statins. GAUSS-1, GAUSS-2 and GAUSS-3 trials showed that PCSK9i could effectively reduce the risk of muscle adverse events in patients with statin intolerance compared with ezetimibe (Sullivan et al., 2012; Stroes et al., 2014; Nissen et al., 2016). Although the price of PCSK9i is presently higher than that of other drugs and less costeffectiveness in general patients, the beneficial effects of these inhibitors are well documented, especially in patients with statin intolerance and familial hypercholesterolemia (Azari et al., 2020). In the future, the price of PCSK9i should be adjusted within the acceptable range of patients, which will help to bring greater cost-effectiveness and more clinical benefits.

The advantages of this network meta-analysis are that statins were divided into different intensities and compared with the commonly lipid-lowering drugs. Besides, the included studies were randomized controlled trials, which enhanced the reliability of the results. At the same time, our analysis provides evidence to support the ability of PCSK9i to reduce mortality. However, there are several intrinsic limitations. Firstly, our network metaanalysis was unable to assess primary prevention in isolation because there are not adequate studies using PCSK9i and ezetimibe in primary prevention, and the definition of primary prevention is different across studies (Naci et al., 2013; Yebyo et al., 2019), which can affect the results in this network metaanalysis. Secondly, we only analyzed all-cause mortality and cardiovascular mortality in secondary prevention, as traditional meta-analysis has confirmed the positive effects of lipid-lowering therapy on MACE. Thirdly, statins were divided into three intensities but there was no further analysis of the different types of statins that were involved. Besides, we could not analyze these endpoint events, as the adverse events, such as metabolic disorder syndrome and cognitive disorders, were only reported in few studies.

\section{CONCLUSION}

In summary, the findings of our network meta-analysis have important clinical implications. We found that 1) more intensive treatment compared with less intensive treatment was associated with a greater risk reduction in all-cause mortality, MACE, and coronary revascularization; 2) PCSK9i added to background statins was ranked as the most effective treatment in reducing these outcomes, and PCSK9i did not increase the additional risk of new-onset diabetes; 3) LT could be recommended as the initial therapy; 4) the beneficial effects of ezetimibe on clinical outcomes were not superior to those of statins; and 5) clinicians should pay attention to the risk of newonset diabetes when using moderate-to-high intensity statins. 
Lastly, lipid-lowering drugs were not associated with the development of cancer.

\section{DATA AVAILABILITY STATEMENT}

The original contributions presented in the study are included in the article/Supplementary Material, further inquiries can be directed to the corresponding authors.

\section{AUTHOR CONTRIBUTIONS}

WM contributed to the conception and design the work. WM, QP, DP, and TX contributed to the acquisition, analysis, or interpretation of the data for the work. WM drafted the manuscript. DL and HZ critically revised the manuscript. All authors gave final approval and agree to be accountable for all aspects of work ensuring integrity and accuracy.

\section{REFERENCES}

ALLHAT Collaborative Research Group (2002). Major Outcomes in Moderately Hypercholesterolemic, Hypertensive Patients Randomized to Pravastatin vs Usual Care: The Antihypertensive and Lipid-Lowering Treatment to Prevent Heart Attack Trial (ALLHAT-LLT). Jama 288 (23), 2998-3007. doi:10.1001/ jama.288.23.2998

AlTurki, A., Marafi, M., Dawas, A., Dube, M. P., Vieira, L., Sherman, M. H., et al. (2019). Meta-analysis of Randomized Controlled Trials Assessing the Impact of Proprotein Convertase Subtilisin/Kexin Type 9 Antibodies on Mortality and Cardiovascular Outcomes. Am. J. Cardiol. 124 (12), 1869-1875. doi:10.1016/ j.amjcard.2019.09.011

Amarenco, P., Bogousslavsky, J., Callahan, A., 3rd, Goldstein, L. B., Hennerici, M., Rudolph, A. E., et al. (2006). High-dose Atorvastatin after Stroke or Transient Ischemic Attack. N. Engl. J. Med. 355 (6), 549-559. doi:10.1056/ NEJMoa061894

Armitage, J., Armitage, J., Bowman, L., Wallendszus, K., Bulbulia, R., Rahimi, K., et al. (2010). Intensive Lowering of LDL Cholesterol with $80 \mathrm{Mg}$ versus $20 \mathrm{Mg}$ Simvastatin Daily in 12,064 Survivors of Myocardial Infarction: a Double-Blind Randomised Trial. Lancet 376 (9753), 1658-1669. doi:10.1016/s0140-6736(10)60310-8

Athyros, V. G., Papageorgiou, A. A., Mercouris, B. R., Athyrou, V. V., Symeonidis, A. N., Basayannis, E. O., et al. (2002). Treatment with Atorvastatin to the National Cholesterol Educational Program Goal versus 'usual' Care in Secondary Coronary Heart Disease Prevention. The Greek Atorvastatin and Coronary-Heart-Disease Evaluation (GREACE) Study. Curr. Med. Res. Opin. 18 (4), 220-228. doi:10.1185/030079902125000787

Azari, S., Rezapour, A., Omidi, N., Alipour, V., Behzadifar, M., Safari, H., et al. (2020). Cost-effectiveness Analysis of PCSK9 Inhibitors in Cardiovascular Diseases: a Systematic Review. Heart Fail. Rev. 25 (6), 1077-1088. doi:10.1007/s10741-019-09874-2

Baigent, C., Landray, M. J., Reith, C., Emberson, J., Wheeler, D. C., Tomson, C., et al. (2011). The Effects of Lowering LDL Cholesterol with Simvastatin Plus Ezetimibe in Patients with Chronic Kidney Disease (Study of Heart and Renal Protection): a Randomised Placebo-Controlled Trial. Lancet 377 (9784), 2181-2192. doi:10.1016/s0140-6736(11)60739-3

Bonovas, S., Nikolopoulos, G., and Sitaras, N. M. (2011). Efficacy and Safety of More Intensive Lowering of LDL Cholesterol. Lancet 377 (9767), 715-716. doi:10.1016/s0140-6736(11)60261-4

Cannon, C. P., Blazing, M. A., Giugliano, R. P., McCagg, A., White, J. A., Theroux, P., et al. (2015). Ezetimibe Added to Statin Therapy after Acute Coronary Syndromes. N. Engl. J. Med. 372 (25), 2387-2397. doi:10.1056/ NEJMoa1410489

Cannon, C. P., Braunwald, E., McCabe, C. H., Rader, D. J., Rouleau, J. L., Belder, R., et al. (2004). Intensive versus Moderate Lipid Lowering with Statins after Acute

\section{FUNDING}

This work was supported by the National Natural Science Foundation of China (81570326) and the Science and Technology Innovation Special Fund of Xuzhou Science and Technology Bureau (KC17094).

\section{ACKNOWLEDGMENTS}

Thanks to Ping Zeng, associate professor of Xuzhou Medical University, for his assistance with statical analysis.

\section{SUPPLEMENTARY MATERIAL}

The Supplementary Material for this article can be found online at: https://www.frontiersin.org/articles/10.3389/fphar.2021.713007/ full\#supplementary-material

Coronary Syndromes. N. Engl. J. Med. 350 (15), 1495-1504. doi:10.1056/ NEJMoa040583

Cannon, C. P., Cariou, B., Blom, D., McKenney, J. M., Lorenzato, C., Pordy, R., et al. (2015). Efficacy and Safety of Alirocumab in High Cardiovascular Risk Patients with Inadequately Controlled Hypercholesterolaemia on Maximally Tolerated Doses of Statins: the ODYSSEY COMBO II Randomized Controlled Trial. Eur. Heart J. 36 (19), 1186-1194. doi:10.1093/eurheartj/ehv028

Chiu, S. W., Pratt, C. M., Feinn, R., and Chatterjee, S. (2020). Proprotein Convertase Subtilisin/Kexin Type 9 Inhibitors and Ezetimibe on Risk of New-Onset Diabetes: A Systematic Review and Meta-Analysis of Large, Double-Blinded Randomized Controlled Trials. J. Cardiovasc. Pharmacol. Ther. 25 (5), 409-417. doi:10.1177/1074248420924983

Colhoun, H. M., Betteridge, D. J., Durrington, P. N., Hitman, G. A., Neil, H. A., Livingstone, S. J., et al. (2004). Primary Prevention of Cardiovascular Disease with Atorvastatin in Type 2 Diabetes in the Collaborative Atorvastatin Diabetes Study (CARDS): Multicentre Randomised Placebo-Controlled Trial. Lancet 364 (9435), 685-696. doi:10.1016/s0140-6736(04)16895-5

Collaboration, C. T. T. (2019). Efficacy and Safety of Statin Therapy in Older People: a Meta-Analysis of Individual Participant Data from 28 Randomised Controlled Trials. Lancet 393 (10170), 407-415. doi:10.1016/s0140-6736(18) 31942-1

Crouse, J. R., 3rd, Raichlen, J. S., Riley, W. A., Evans, G. W., Palmer, M. K., O’Leary, D. H., et al. (2007). Effect of Rosuvastatin on Progression of Carotid Intimamedia Thickness in Low-Risk Individuals with Subclinical Atherosclerosis: the METEOR Trial. Jama 297 (12), 1344-1353. doi:10.1001/jama.297.12.1344

Da Dalt, L., Ruscica, M., Bonacina, F., Balzarotti, G., Dhyani, A., Di Cairano, E., et al. (2019). PCSK9 Deficiency Reduces Insulin Secretion and Promotes Glucose Intolerance: the Role of the Low-Density Lipoprotein Receptor. Eur. Heart J. 40 (4), 357-368. doi:10.1093/eurheartj/ehy357

de Lemos, J. A., Blazing, M. A., Wiviott, S. D., Lewis, E. F., Fox, K. A., White, H. D., et al. (2004). Early Intensive vs a Delayed Conservative Simvastatin Strategy in Patients with Acute Coronary Syndromes: Phase Z of the A to Z Trial. Jama 292 (11), 1307-1316. doi:10.1001/jama.292.11.1307

Diaz, R., Li, Q. H., Bhatt, D. L., Bittner, V. A., Baccara-Dinet, M. T., Goodman, S. G., et al. (2021). Intensity of Statin Treatment after Acute Coronary Syndrome, Residual Risk, and its Modification by Alirocumab: Insights from the ODYSSEY OUTCOMES Trial. Eur. J. Prev. Cardiol. 28 (1), 33-43. doi:10.1177/2047487320941987

Downs, J. R., Clearfield, M., Weis, S., Whitney, E., Shapiro, D. R., Beere, P. A., et al. (1998). Primary Prevention of Acute Coronary Events with Lovastatin in Men and Women with Average Cholesterol Levels: Results of AFCAPS/TexCAPS. Air Force/Texas Coronary Atherosclerosis Prevention Study. Jama 279 (20), 1615-1622. doi:10.1001/jama.279.20.1615

Fellström, B. C., Jardine, A. G., Schmieder, R. E., Holdaas, H., Bannister, K., Beutler, J., et al. (2009). Rosuvastatin and Cardiovascular Events in Patients Undergoing 
Hemodialysis. N. Engl. J. Med. 360 (14), 1395-1407. doi:10.1056/ NEJMoa0810177

Gencer, B., Mach, F., Guo, J., Im, K., Ruzza, A., Wang, H., et al. (2020). Cognition after Lowering LDL-Cholesterol with Evolocumab. J. Am. Coll. Cardiol. 75 (18), 2283-2293. doi:10.1016/j.jacc.2020.03.039

Gencer, B., Marston, N. A., Im, K., Cannon, C. P., Sever, P., Keech, A., et al. (2020). Efficacy and Safety of Lowering LDL Cholesterol in Older Patients: a Systematic Review and Meta-Analysis of Randomised Controlled Trials. Lancet 396 (10263), 1637-1643. doi:10.1016/s0140-6736(20)32332-1

Gouverneur, A., Sanchez-Pena, P., Veyrac, G., Salem, J.-E., Bégaud, B., and Bezin, J. (2021). Neurocognitive Disorders Associated with PCSK9 Inhibitors: a Pharmacovigilance Disproportionality Analysis. Cardiovasc. Drugs Ther. doi:10.1007/s10557-021-07242-7

Group, H. P. S. C. (2002). MRC/BHF Heart Protection Study of Cholesterol Lowering with Simvastatin in 20,536 High-Risk Individuals: a Randomised Placebo-Controlled Trial. Lancet 360 (9326), 7-22. doi:10.1016/s0140-6736(02) 09327-3

Group, L. S. (1998). Prevention of Cardiovascular Events and Death with Pravastatin in Patients with Coronary Heart Disease and a Broad Range of Initial Cholesterol Levels. N. Engl. J. Med. 339 (19), 1349-1357. doi:10.1056/ nejm199811053391902

Group, S. (1994). Randomised Trial of Cholesterol Lowering in 4444 Patients with Coronary Heart Disease: the Scandinavian Simvastatin Survival Study (4S). Lancet 344 (8934), 1383-1389.

Guedeney, P., Sorrentino, S., Giustino, G., Chapelle, C., Laporte, S., Claessen, B. E., et al. (2021). Indirect Comparison of the Efficacy and Safety of Alirocumab and Evolocumab: a Systematic Review and Network Meta-Analysis. Eur. Heart J. Cardiovasc. Pharmacother. 7 (3), 225-235. doi:10.1093/ehjcvp/pvaa024

Hagiwara, N., Kawada-Watanabe, E., Koyanagi, R., Arashi, H., Yamaguchi, J., Nakao, K., et al. (2017). Low-density Lipoprotein Cholesterol Targeting with Pitavastatin + Ezetimibe for Patients with Acute Coronary Syndrome and Dyslipidaemia: the HIJ-PROPER Study, a Prospective, Open-Label, Randomized Trial. Eur. Heart J. 38 (29), 2264-2276. doi:10.1093/eurheartj/ ehx162

Harvey, P. D., Sabbagh, M. N., Harrison, J. E., Ginsberg, H. N., Chapman, M. J., Manvelian, G., et al. (2018). No Evidence of Neurocognitive Adverse Events Associated with Alirocumab Treatment in 3340 Patients from 14 Randomized Phase 2 and 3 Controlled Trials: a Meta-Analysis of Individual Patient Data. Eur. Heart J. 39 (5), 374-381. doi:10.1093/eurheartj/ehx661

Hirsh Raccah, B., Yanovsky, A., Treves, N., Rotshild, V., Renoux, C., Danenberg, H., et al. (2021). Proprotein Convertase Subtilisin/Kexin Type 9 (PCSK9) Inhibitors and the Risk for Neurocognitive Adverse Events: A Systematic Review, Meta-Analysis and Meta-Regression. Int. J. Cardiol. 335, 7-14. doi:10.1016/j.ijcard.2021.04.025

Hoang, T., and Kim, J. (2020). Comparative Effect of Statins and Omega-3 Supplementation on Cardiovascular Events: Meta-Analysis and Network Meta-Analysis of 63 Randomized Controlled Trials Including 264,516 Participants. Nutrients 12 (8). doi:10.3390/nu12082218

Holdaas, H., Fellström, B., Jardine, A. G., Holme, I., Nyberg, G., Fauchald, P., et al. (2003). Effect of Fluvastatin on Cardiac Outcomes in Renal Transplant Recipients: a Multicentre, Randomised, Placebo-Controlled Trial. Lancet 361 (9374), 2024-2031. doi:10.1016/s0140-6736(03)13638-0

Hosomi, N., Nagai, Y., Kohriyama, T., Ohtsuki, T., Aoki, S., Nezu, T., et al. (2015). The Japan Statin Treatment against Recurrent Stroke (J-STARS): A Multicenter, Randomized, Open-Label, Parallel-Group Study. EBioMedicine 2 (9), 1071-1078. doi:10.1016/j.ebiom.2015.08.006

Investigators, G. P. (2000). Results of the Low-Dose (20 Mg) Pravastatin GISSI Prevenzione Trial in 4271 Patients with Recent Myocardial Infarction: Do Stopped Trials Contribute to Overall Knowledge? GISSI Prevenzione Investigators (Gruppo Italiano Per Lo Studio Della Sopravvivenza nell'Infarto Miocardico). Ital. Heart J. 1 (12), 810-820.

Janik, M. J., Urbach, D. V., van Nieuwenhuizen, E., Zhao, J., Yellin, O., BaccaraDinet, M. T., et al. (2021). Alirocumab Treatment and Neurocognitive Function According to the CANTAB Scale in Patients at Increased Cardiovascular Risk: A Prospective, Randomized, Placebo-Controlled Study. Atherosclerosis 331, 20-27. doi:10.1016/j.atherosclerosis.2021.06.913

Johannesen, C. D. L., Mortensen, M. B., Langsted, A., and Nordestgaard, B. G. (2021). Apolipoprotein B and Non-HDL Cholesterol Better Reflect Residual
Risk Than LDL Cholesterol in Statin-Treated Patients. J. Am. Coll. Cardiol. 77 (11), 1439-1450. doi:10.1016/j.jacc.2021.01.027

Jukema, J. W., Bruschke, A. V., van Boven, A. J., Reiber, J. H., Bal, E. T., Zwinderman, A. H., et al. (1995). Effects of Lipid Lowering by Pravastatin on Progression and Regression of Coronary Artery Disease in Symptomatic Men with normal to Moderately Elevated Serum Cholesterol Levels. The Regression Growth Evaluation Statin Study (REGRESS). Circulation 91 (10), 2528-2540. doi:10.1161/01.cir.91.10.2528

Kastelein, J. J., Akdim, F., Stroes, E. S., Zwinderman, A. H., Bots, M. L., Stalenhoef, A. F., et al. (2008). Simvastatin with or without Ezetimibe in Familial Hypercholesterolemia. N. Engl. J. Med. 358 (14), 1431-1443. doi:10.1056/ NEJMoa0800742

Khan, A. R., Bavishi, C., Riaz, H., Farid, T. A., Khan, S., Atlas, M., et al. (2017). Increased Risk of Adverse Neurocognitive Outcomes with Proprotein Convertase Subtilisin-Kexin Type 9 Inhibitors. Circ. Cardiovasc. Qual. Outcomes 10 (1). doi:10.1161/circoutcomes.116.003153

Khan, S. A., Naz, A., Qamar Masood, M., and Shah, R. (2020). Meta-Analysis of Inclisiran for the Treatment of Hypercholesterolemia. Am. J. Cardiol. 134, 69-73. doi:10.1016/j.amjcard.2020.08.018

Khan, S. U., Rahman, H., Okunrintemi, V., Riaz, H., Khan, M. S., Sattur, S., et al. (2019). Association of Lowering Low-Density Lipoprotein Cholesterol with Contemporary Lipid-Lowering Therapies and Risk of Diabetes Mellitus: A Systematic Review and Meta-Analysis. J. Am. Heart Assoc. 8 (7), e011581. doi:10.1161/jaha.118.011581

Khan, S. U., Talluri, S., Riaz, H., Rahman, H., Nasir, F., Bin Riaz, I., et al. (2018). A Bayesian Network Meta-Analysis of PCSK9 Inhibitors, Statins and Ezetimibe with or without Statins for Cardiovascular Outcomes. Eur. J. Prev. Cardiol. 25 (8), 844-853. doi:10.1177/2047487318766612

Kim, J., Hoang, T., Kim, J. M., Bu, S. Y., Choi, J. H., Park, E., et al. (2020). All-Cause Mortality and Cardiovascular Death between Statins and Omega-3 Supplementation: A Meta-Analysis and Network Meta-Analysis from 55 Randomized Controlled Trials. Nutrients 12 (10). doi:10.3390/nu12103203

Kjekshus, J., Apetrei, E., Barrios, V., Böhm, M., Cleland, J. G., Cornel, J. H., et al. (2007). Rosuvastatin in Older Patients with Systolic Heart Failure. N. Engl. J. Med. 357 (22), 2248-2261. doi:10.1056/NEJMoa0706201

Knopp, R. H., d'Emden, M., Smilde, J. G., and Pocock, S. J. (2006). Efficacy and Safety of Atorvastatin in the Prevention of Cardiovascular End Points in Subjects with Type 2 Diabetes: the Atorvastatin Study for Prevention of Coronary Heart Disease Endpoints in Non-insulin-dependent Diabetes Mellitus (ASPEN). Diabetes Care 29 (7), 1478-1485. doi:10.2337/dc05-2415

Koren, M. J., and Hunninghake, D. B. (2004). Clinical Outcomes in Managed-Care Patients with Coronary Heart Disease Treated Aggressively in Lipid-Lowering Disease Management Clinics: the alliance Study. J. Am. Coll. Cardiol. 44 (9), 1772-1779. doi:10.1016/j.jacc.2004.07.053

Lamina, C., and Kronenberg, F. (2019). Estimation of the Required Lipoprotein(a)Lowering Therapeutic Effect Size for Reduction in Coronary Heart Disease Outcomes: A Mendelian Randomization Analysis. JAMA Cardiol. 4 (6), 575-579. doi:10.1001/jamacardio.2019.1041

LaRosa, J. C., Grundy, S. M., Waters, D. D., Shear, C., Barter, P., Fruchart, J. C., et al. (2005). Intensive Lipid Lowering with Atorvastatin in Patients with Stable Coronary Disease. N. Engl. J. Med. 352 (14), 1425-1435. doi:10.1056/NEJMoa050461

Liem, A. H., van Boven, A. J., Veeger, N. J., Withagen, A. J., Robles de Medina, R. M., Tijssen, J. G., et al. (2002). Effect of Fluvastatin on Ischaemia Following Acute Myocardial Infarction: a Randomized Trial. Eur. Heart J. 23 (24), 1931-1937. doi:10.1053/euhj.2002.3291

Macchi, C., Favero, C., Ceresa, A., Vigna, L., Conti, D. M., Pesatori, A. C., et al. (2020). Depression and Cardiovascular Risk-Association Among Beck Depression Inventory, PCSK9 Levels and Insulin Resistance. Cardiovasc. Diabetol. 19 (1), 187. doi:10.1186/s12933-020-01158-6

Mach, F., Baigent, C., Catapano, A. L., Koskinas, K. C., Casula, M., Badimon, L., et al. (2020). 2019 ESC/EAS Guidelines for the Management of Dyslipidaemias: Lipid Modification to Reduce Cardiovascular Risk. Eur. Heart J. 41 (1), 111-188. doi:10.1093/eurheartj/ehz455

Moher, D., Liberati, A., Tetzlaff, J., and Altman, D. G. (2009). Preferred Reporting Items for Systematic Reviews and Meta-Analyses: the PRISMA Statement. Bmj 339, b2535. doi:10.1136/bmj.b2535

Naci, H., Brugts, J. J., Fleurence, R., Tsoi, B., Toor, H., and Ades, A. E. (2013). Comparative Benefits of Statins in the Primary and Secondary Prevention of 
Major Coronary Events and All-Cause Mortality: a Network Meta-Analysis of Placebo-Controlled and Active-Comparator Trials. Eur. J. Prev. Cardiol. 20 (4), 641-657. doi:10.1177/2047487313480435

Nakamura, H., Arakawa, K., Itakura, H., Kitabatake, A., Goto, Y., Toyota, T., et al. (2006). Primary Prevention of Cardiovascular Disease with Pravastatin in Japan (MEGA Study): a Prospective Randomised Controlled Trial. Lancet 368 (9542), 1155-1163. doi:10.1016/s0140-6736(06)69472-5

Navarese, E. P., Robinson, J. G., Kowalewski, M., Kolodziejczak, M., Andreotti, F., Bliden, K., et al. (2018). Association between Baseline LDL-C Level and Total and Cardiovascular Mortality after LDL-C Lowering: A Systematic Review and Meta-Analysis. Jama 319 (15), 1566-1579. doi:10.1001/jama.2018.2525

Nicholls, S. J., Puri, R., Anderson, T., Ballantyne, C. M., Cho, L., Kastelein, J. J., et al. (2016). Effect of Evolocumab on Progression of Coronary Disease in StatinTreated Patients: The GLAGOV Randomized Clinical Trial. Jama 316 (22), 2373-2384. doi:10.1001/jama.2016.16951

Nissen, S. E., Stroes, E., Dent-Acosta, R. E., Rosenson, R. S., Lehman, S. J., Sattar, N., et al. (2016). Efficacy and Tolerability of Evolocumab vs Ezetimibe in Patients with Muscle-Related Statin Intolerance: The GAUSS-3 Randomized Clinical Trial. Jama 315 (15), 1580-1590. doi:10.1001/jama.2016.3608

Nissen, S. E., Tuzcu, E. M., Schoenhagen, P., Brown, B. G., Ganz, P., Vogel, R. A., et al. (2004). Effect of Intensive Compared with Moderate Lipid-Lowering Therapy on Progression of Coronary Atherosclerosis: a Randomized Controlled Trial. Jama 291 (9), 1071-1080. doi:10.1001/jama.291.9.1071

O’Donoghue, M. L., Fazio, S., Giugliano, R. P., Stroes, E. S. G., Kanevsky, E., Gouni-Berthold, I., et al. (2019). Lipoprotein(a), PCSK9 Inhibition, and Cardiovascular Risk. Circulation 139 (12), 1483-1492. doi:10.1161/ circulationaha.118.037184

Patients, h. P. M. S. G. f. C. R. (1993). Effects of Pravastatin in Patients with Serum Total Cholesterol Levels from 5.2 to $7.8 \mathrm{Mmol} / \mathrm{liter}$ (200 to $300 \mathrm{Mg} / \mathrm{dl}$ ) Plus Two Additional Atherosclerotic Risk Factors. The Pravastatin Multinational Study Group for Cardiac Risk Patients. Am. J. Cardiol. 72 (14), 1031-1037. doi:10.1016/0002-9149(93)90858-a

Pedersen, T. R., Faergeman, O., Kastelein, J. J., Olsson, A. G., Tikkanen, M. J., Holme, I., et al. (2005). High-dose Atorvastatin vs Usual-Dose Simvastatin for Secondary Prevention after Myocardial Infarction: the IDEAL Study: a Randomized Controlled Trial. Jama 294 (19), 2437-2445. doi:10.1001/ jama.294.19.2437

Raal, F. J., Rosenson, R. S., Reeskamp, L. F., Hovingh, G. K., Kastelein, J. J. P., Rubba, P., et al. (2020). Evinacumab for Homozygous Familial Hypercholesterolemia. N. Engl. J. Med. 383 (8), 711-720. doi:10.1056/NEJMoa2004215

Reiner, Ž. (2018). PCSK9 Inhibitors in Clinical Practice: Expectations and Reality. Atherosclerosis 270, 187-188. doi:10.1016/j.atherosclerosis.2018.01.001

Reiner, Ž. (2013). Statins in the Primary Prevention of Cardiovascular Disease. Nat. Rev. Cardiol. 10 (8), 453-464. doi:10.1038/nrcardio.2013.80

Ridker, P. M., Danielson, E., Fonseca, F. A., Genest, J., Gotto, A. M., Jr., Kastelein, J. J., et al. (2008). Rosuvastatin to Prevent Vascular Events in Men and Women with Elevated C-Reactive Protein. N. Engl. J. Med. 359 (21), 2195-2207. doi:10.1056/NEJMoa0807646

Ridker, P. M., Revkin, J., Amarenco, P., Brunell, R., Curto, M., Civeira, F., et al. (2017). Cardiovascular Efficacy and Safety of Bococizumab in High-Risk Patients. N. Engl. J. Med. 376 (16), 1527-1539. doi:10.1056/NEJMoa1701488

Robinson, J. G., Farnier, M., Krempf, M., Bergeron, J., Luc, G., Averna, M., et al. (2015). Efficacy and Safety of Alirocumab in Reducing Lipids and Cardiovascular Events. N. Engl. J. Med. 372 (16), 1489-1499. doi:10.1056/ NEJMoa1501031

Rossebø, A. B., Pedersen, T. R., Boman, K., Brudi, P., Chambers, J. B., Egstrup, K., et al. (2008). Intensive Lipid Lowering with Simvastatin and Ezetimibe in Aortic Stenosis. N. Engl. J. Med. 359 (13), 1343-1356. doi:10.1056/ NEJMoa0804602

Ruscica, M., Ferri, N., Santos, R. D., Sirtori, C. R., and Corsini, A. (2021). Lipid Lowering Drugs: Present Status and Future Developments. Curr. Atheroscler. Rep. 23 (5), 17. doi:10.1007/s11883-021-00918-3

Ruscica, M., Sirtori, C. R., Corsini, A., Watts, G. F., and Sahebkar, A. (2021). Lipoprotein(a): Knowns, Unknowns and Uncertainties. Pharmacol. Res. 173, 105812. doi:10.1016/j.phrs.2021.105812

Ruscica, M., Tokgözoğlu, L., Corsini, A., and Sirtori, C. R. (2019). PCSK9 Inhibition and Inflammation: A Narrative Review. Atherosclerosis 288, 146-155. doi:10.1016/j.atherosclerosis.2019.07.015
Sabatine, M. S., Giugliano, R. P., Keech, A. C., Honarpour, N., Wiviott, S. D., Murphy, S. A., et al. (2017). Evolocumab and Clinical Outcomes in Patients with Cardiovascular Disease. N. Engl. J. Med. 376 (18), 1713-1722. doi:10.1056/ NEJMoa1615664

Sabatine, M. S., Giugliano, R. P., Wiviott, S. D., Raal, F. J., Blom, D. J., Robinson, J., et al. (2015). Efficacy and Safety of Evolocumab in Reducing Lipids and Cardiovascular Events. N. Engl. J. Med. 372 (16), 1500-1509. doi:10.1056/ NEJMoa1500858

Sabatine, M. S., Leiter, L. A., Wiviott, S. D., Giugliano, R. P., Deedwania, P., De Ferrari, G. M., et al. (2017). Cardiovascular Safety and Efficacy of the PCSK9 Inhibitor Evolocumab in Patients with and without Diabetes and the Effect of Evolocumab on Glycaemia and Risk of New-Onset Diabetes: a Prespecified Analysis of the FOURIER Randomised Controlled Trial. Lancet Diabetes Endocrinol. 5 (12), 941-950. doi:10.1016/s2213-8587(17)30313-3

Sacks, F. M., Pfeffer, M. A., Moye, L. A., Rouleau, J. L., Rutherford, J. D., Cole, T. G., et al. (1996). The Effect of Pravastatin on Coronary Events after Myocardial Infarction in Patients with Average Cholesterol Levels. Cholesterol and Recurrent Events Trial Investigators. N. Engl. J. Med. 335 (14), 1001-1009. doi:10.1056/nejm199610033351401

Schmidt, A. F., Carter, J. L., Pearce, L. S., Wilkins, J. T., Overington, J. P., Hingorani, A. D., et al. (2020). PCSK9 Monoclonal Antibodies for the Primary and Secondary Prevention of Cardiovascular Disease. Cochrane Database Syst. Rev. 10 (10), Cd011748. doi:10.1002/14651858.CD011748.pub3

Schwartz, G. G., Steg, P. G., Szarek, M., Bhatt, D. L., Bittner, V. A., Diaz, R., et al. (2018). Alirocumab and Cardiovascular Outcomes after Acute Coronary Syndrome. N. Engl. J. Med. 379 (22), 2097-2107. doi:10.1056/NEJMoa1801174

Serruys, P. W., de Feyter, P., Macaya, C., Kokott, N., Puel, J., Vrolix, M., et al. (2002). Fluvastatin for Prevention of Cardiac Events Following Successful First Percutaneous Coronary Intervention: a Randomized Controlled Trial. Jama 287 (24), 3215-3222. doi:10.1001/jama.287.24.3215

Sever, P. S., Dahlöf, B., Poulter, N. R., Wedel, H., Beevers, G., Caulfield, M., et al. (2003). Prevention of Coronary and Stroke Events with Atorvastatin in Hypertensive Patients Who Have Average or lower-Than-average Cholesterol Concentrations, in the Anglo-Scandinavian Cardiac Outcomes Trial--Lipid Lowering Arm (ASCOT-LLA): a Multicentre Randomised Controlled Trial. Lancet 361 (9364), 1149-1158. doi:10.1016/s0140-6736(03) 12948-0

Sheehe, P. R. (1966). Combination of Log Relative Risk in Retrospective Studies of Disease. Am. J. Public Health Nations Health 56 (10), 1745-1750. doi:10.2105/ ajph.56.10.1745

Shepherd, J., Blauw, G. J., Murphy, M. B., Bollen, E. L., Buckley, B. M., Cobbe, S. M., et al. (2002). Pravastatin in Elderly Individuals at Risk of Vascular Disease (PROSPER): a Randomised Controlled Trial. Lancet 360 (9346), 1623-1630. doi:10.1016/s0140-6736(02)11600-x

Shepherd, J., Cobbe, S. M., Ford, I., Isles, C. G., Lorimer, A. R., MacFarlane, P. W., et al. (1995). Prevention of Coronary Heart Disease with Pravastatin in Men with Hypercholesterolemia. West of Scotland Coronary Prevention Study Group. N. Engl. J. Med. 333 (20), 1301-1307. doi:10.1056/ nejm199511163332001

Stone, N. J., Robinson, J. G., Lichtenstein, A. H., Bairey Merz, C. N., Blum, C. B., Eckel, R. H., et al. (2014). 2013 ACC/AHA Guideline on the Treatment of Blood Cholesterol to Reduce Atherosclerotic Cardiovascular Risk in Adults: a Report of the American College of Cardiology/American Heart Association Task Force on Practice Guidelines. Circulation 129 (25 Pt B), S1-S45. doi:10.1016/ j.jacc.2013.11.00210.1161/01.cir.0000437738.63853.7a

Stroes, E., Colquhoun, D., Sullivan, D., Civeira, F., Rosenson, R. S., Watts, G. F., et al. (2014). Anti-PCSK9 Antibody Effectively Lowers Cholesterol in Patients with Statin Intolerance: the GAUSS-2 Randomized, Placebo-Controlled Phase 3 Clinical Trial of Evolocumab. J. Am. Coll. Cardiol. 63 (23), 2541-2548. doi:10.1016/j.jacc.2014.03.019

Sullivan, D., Olsson, A. G., Scott, R., Kim, J. B., Xue, A., Gebski, V., et al. (2012). Effect of a Monoclonal Antibody to PCSK9 on Low-Density Lipoprotein Cholesterol Levels in Statin-Intolerant Patients: the GAUSS Randomized Trial. Jama 308 (23), 2497-2506. doi:10.1001/jama.2012.25790

Tavazzi, L., Maggioni, A. P., Marchioli, R., Barlera, S., Franzosi, M. G., Latini, R., et al. (2008). Effect of Rosuvastatin in Patients with Chronic Heart Failure (The GISSI-HF Trial): a Randomised, Double-Blind, Placebo-Controlled Trial. Lancet 372 (9645), 1231-1239. doi:10.1016/s0140-6736(08)61240-4 
Toth, P. P., Worthy, G., Gandra, S. R., Sattar, N., Bray, S., Cheng, L. I., et al. (2017). Systematic Review and Network Meta-Analysis on the Efficacy of Evolocumab and Other Therapies for the Management of Lipid Levels in Hyperlipidemia. J. Am. Heart Assoc. 6 (10). doi:10.1161/jaha.116.005367

Wang, S., Cai, R., Yuan, Y., Varghese, Z., Moorhead, J., and Ruan, X. Z. (2017). Association between Reductions in Low-Density Lipoprotein Cholesterol with Statin Therapy and the Risk of New-Onset Diabetes: a Meta-Analysis. Sci. Rep. 7, 39982. doi:10.1038/srep39982

Wanner, C., Krane, V., März, W., Olschewski, M., Mann, J. F., Ruf, G., et al. (2005). Atorvastatin in Patients with Type 2 Diabetes Mellitus Undergoing Hemodialysis. N. Engl. J. Med. 353 (3), 238-248. doi:10.1056/NEJMoa043545

Yebyo, H. G., Aschmann, H. E., Kaufmann, M., and Puhan, M. A. (2019). Comparative Effectiveness and Safety of Statins as a Class and of Specific Statins for Primary Prevention of Cardiovascular Disease: A Systematic Review, Meta-Analysis, and Network Meta-Analysis of Randomized Trials with 94,283 Participants. Am. Heart J. 210, 18-28. doi:10.1016/ j.ahj.2018.12.007

Ying, H., Wang, J., Shen, Z., Wang, M., and Zhou, B. (2021). Impact of Lowering Low-Density Lipoprotein Cholesterol with Contemporary LipidLowering Medicines on Cognitive Function: A Systematic Review and Meta-Analysis. Cardiovasc. Drugs Ther. 35 (1), 153-166. doi:10.1007/ s10557-020-07045-2
Yusuf, S., Bosch, J., Dagenais, G., Zhu, J., Xavier, D., Liu, L., et al. (2016). Cholesterol Lowering in Intermediate-Risk Persons without Cardiovascular Disease. N. Engl. J. Med. 374 (21), 2021-2031. doi:10.1056/NEJMoa1600176

Conflict of Interest: The authors declare that the research was conducted in the absence of any commercial or financial relationships that could be construed as a potential conflict of interest.

Publisher's Note: All claims expressed in this article are solely those of the authors and do not necessarily represent those of their affiliated organizations, or those of the publisher, the editors and the reviewers. Any product that may be evaluated in this article, or claim that may be made by its manufacturer, is not guaranteed or endorsed by the publisher.

Copyright () $2021 \mathrm{Ma}$, Pan, Pan, Xu, Zhu and Li. This is an open-access article distributed under the terms of the Creative Commons Attribution License (CC BY).

The use, distribution or reproduction in other forums is permitted, provided the original author(s) and the copyright owner(s) are credited and that the original publication in this journal is cited, in accordance with accepted academic practice. No use, distribution or reproduction is permitted which does not comply with these terms. 